\title{
RETRACTED ARTICLE: Paediatric Ewing-like sarcoma arising from the cranium - a unique diagnostic challenge
}

\author{
Ian J. Robertson ${ }^{1 *}$, Fadel Bennani ${ }^{2}$, Ronan S. Ryan ${ }^{3}$, Waqar Khan $^{1}$ and M. Kevin Barry ${ }^{1,4}$
}

This article has been retracted by the authors because, contrary to the statement in the article, they did not obtain the necessary written informed consent from the patient's parents to publish this case. The article is no longer available online in order to protect the patient's privacy. The authors have agreed to the retraction.

\section{Author details}

${ }^{1}$ Department of Surgery, Mayo General Hospital, Castlebar, Co Mayo, Ireland. 2Department of Histopathology, Mayo General Hospital, Castlebar, Co Mayo, Ireland. ${ }^{3}$ Department of Diagnostic Radiology, Mayo General Hospital, Castlebar, Co Mayo, Ireland. ${ }^{4}$ Professor of Surgery, National University of Ireland, Galway (NUIG), Galway, Ireland.

Received: 2 February 2016 Accepted: 8 June 2016 Published online: 24 June 2016 


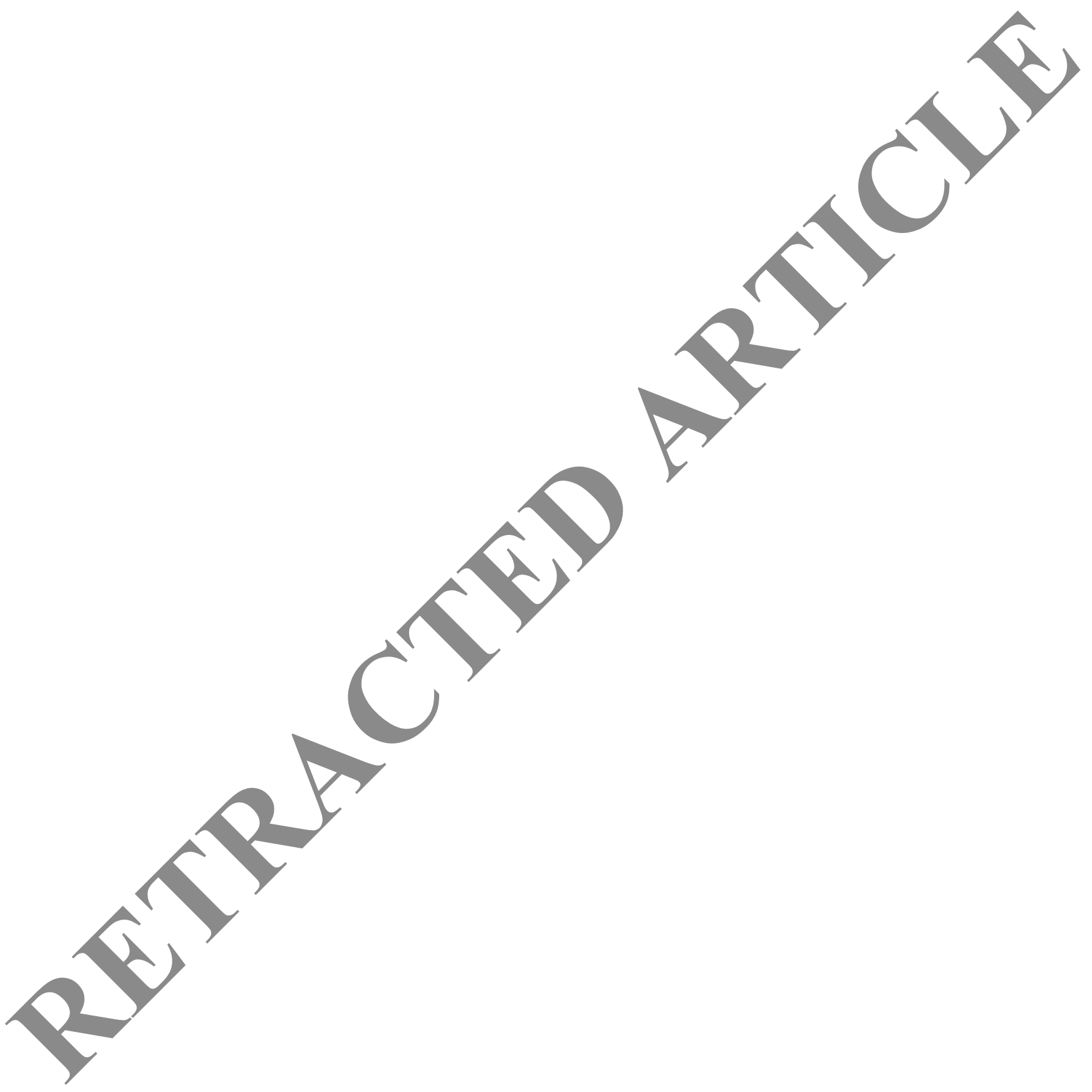




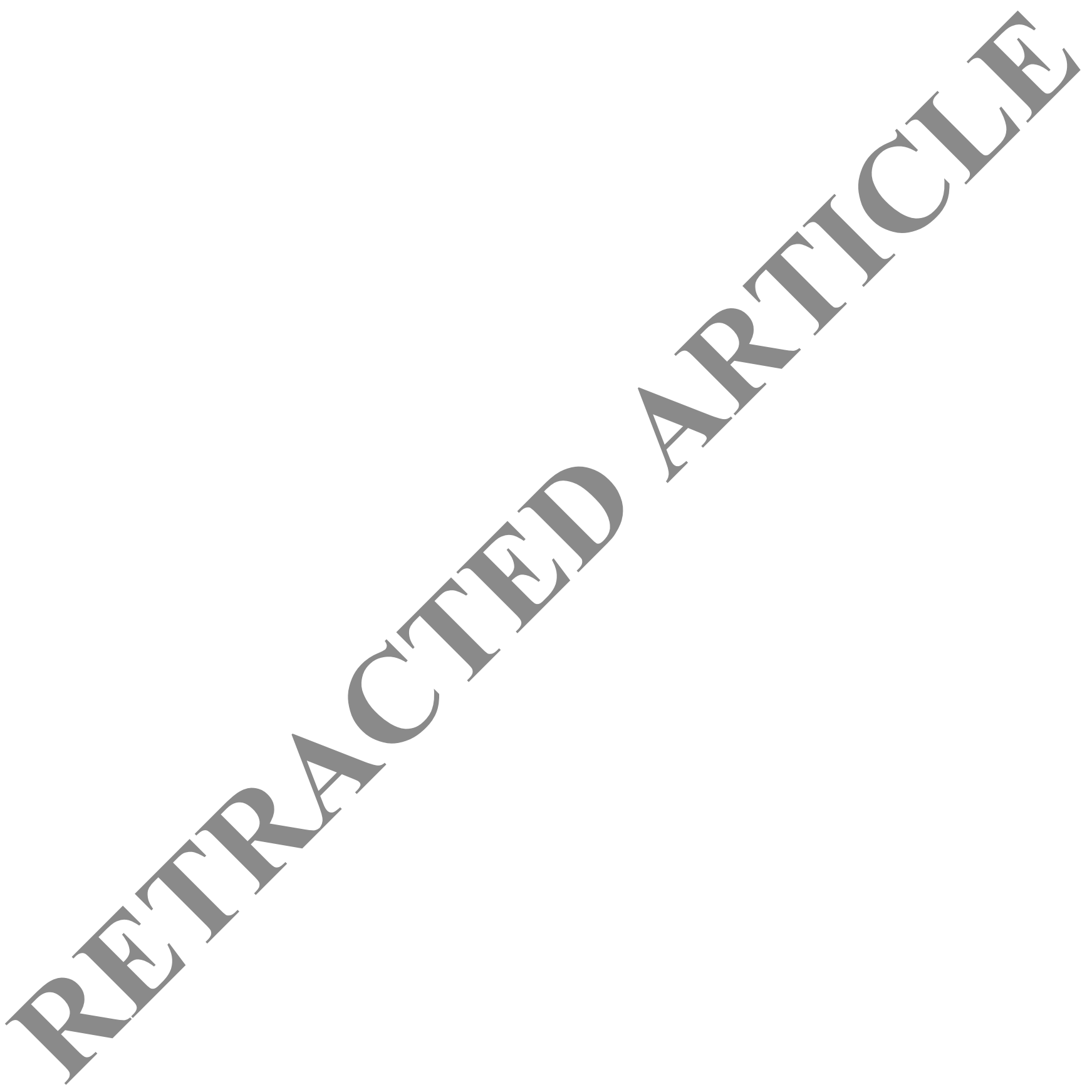




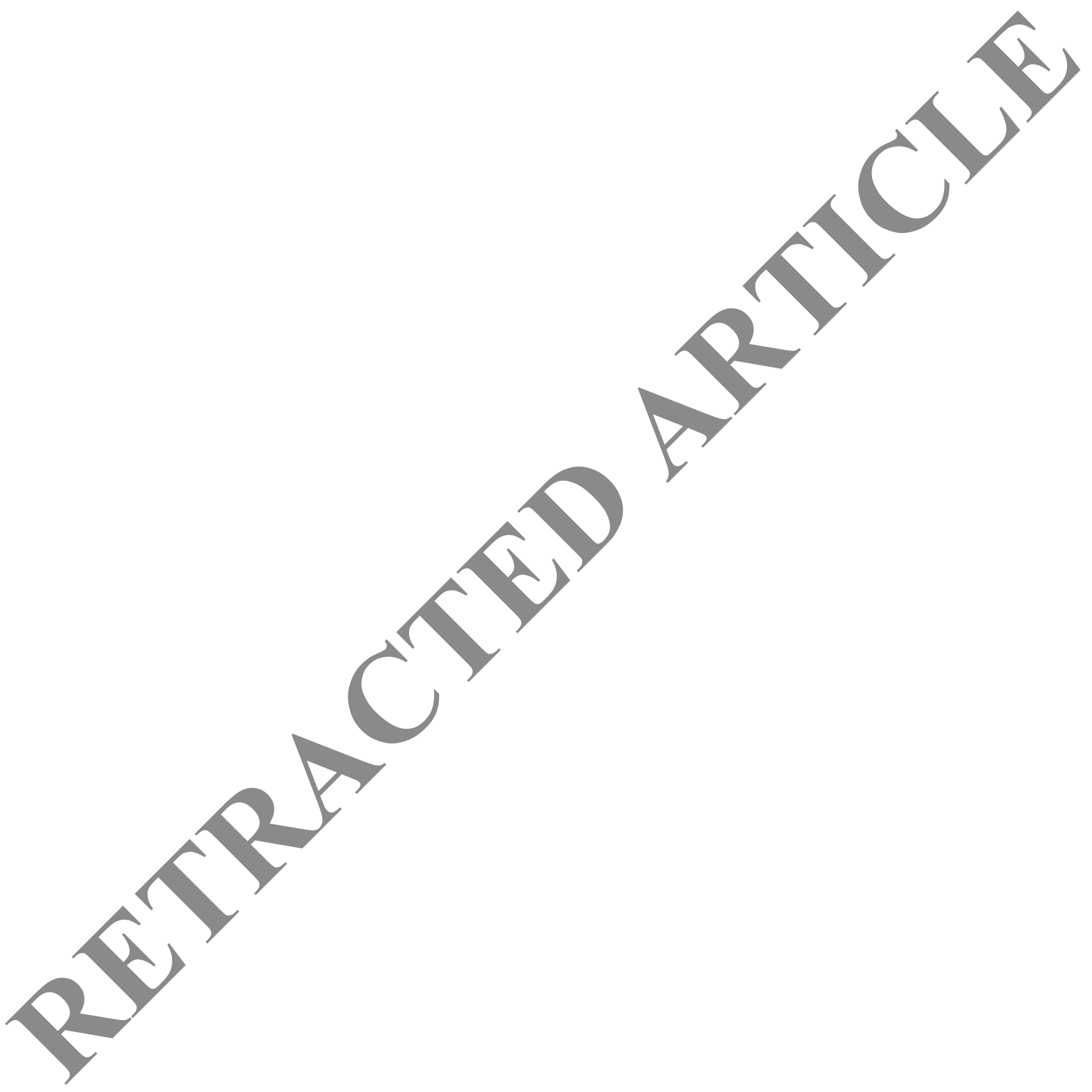




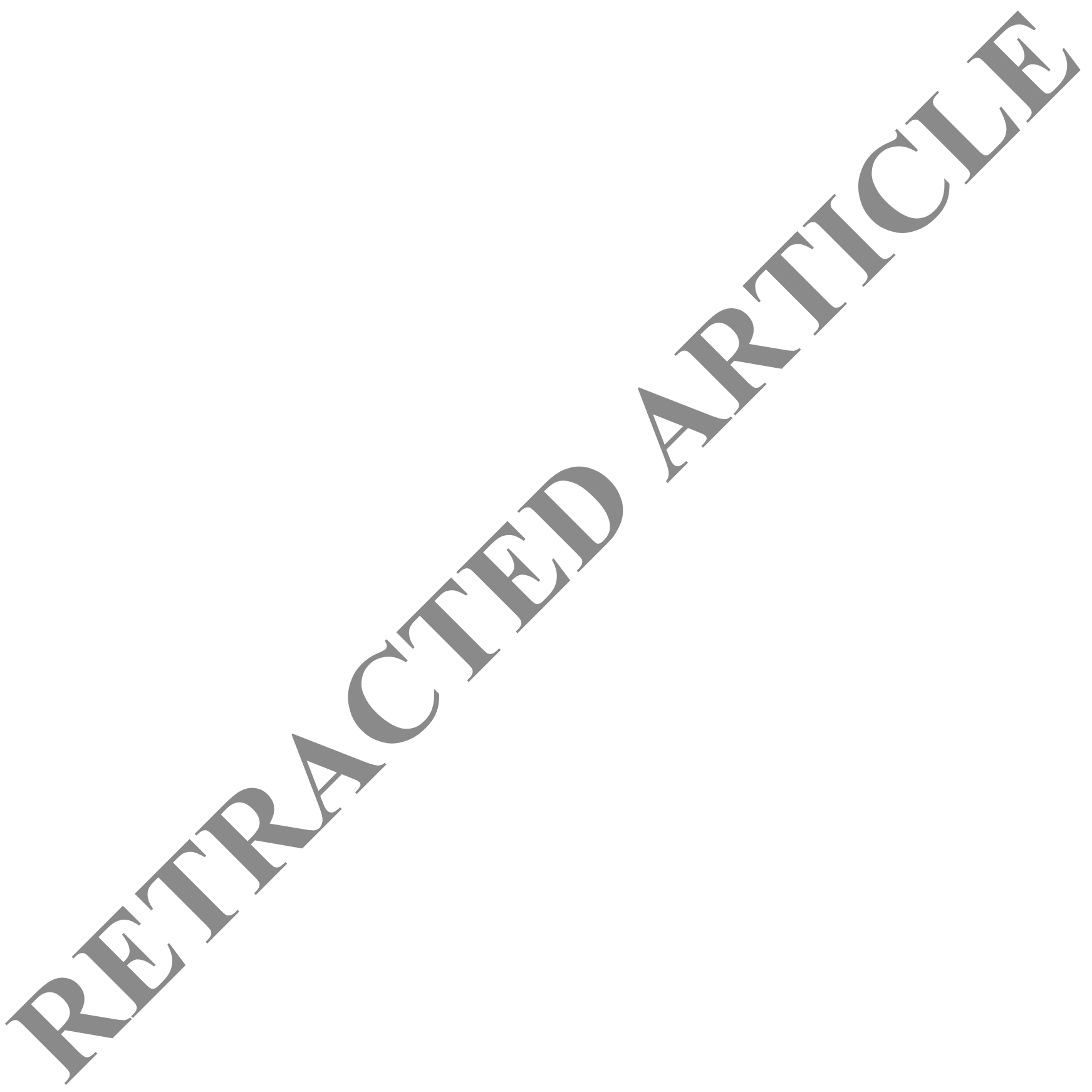




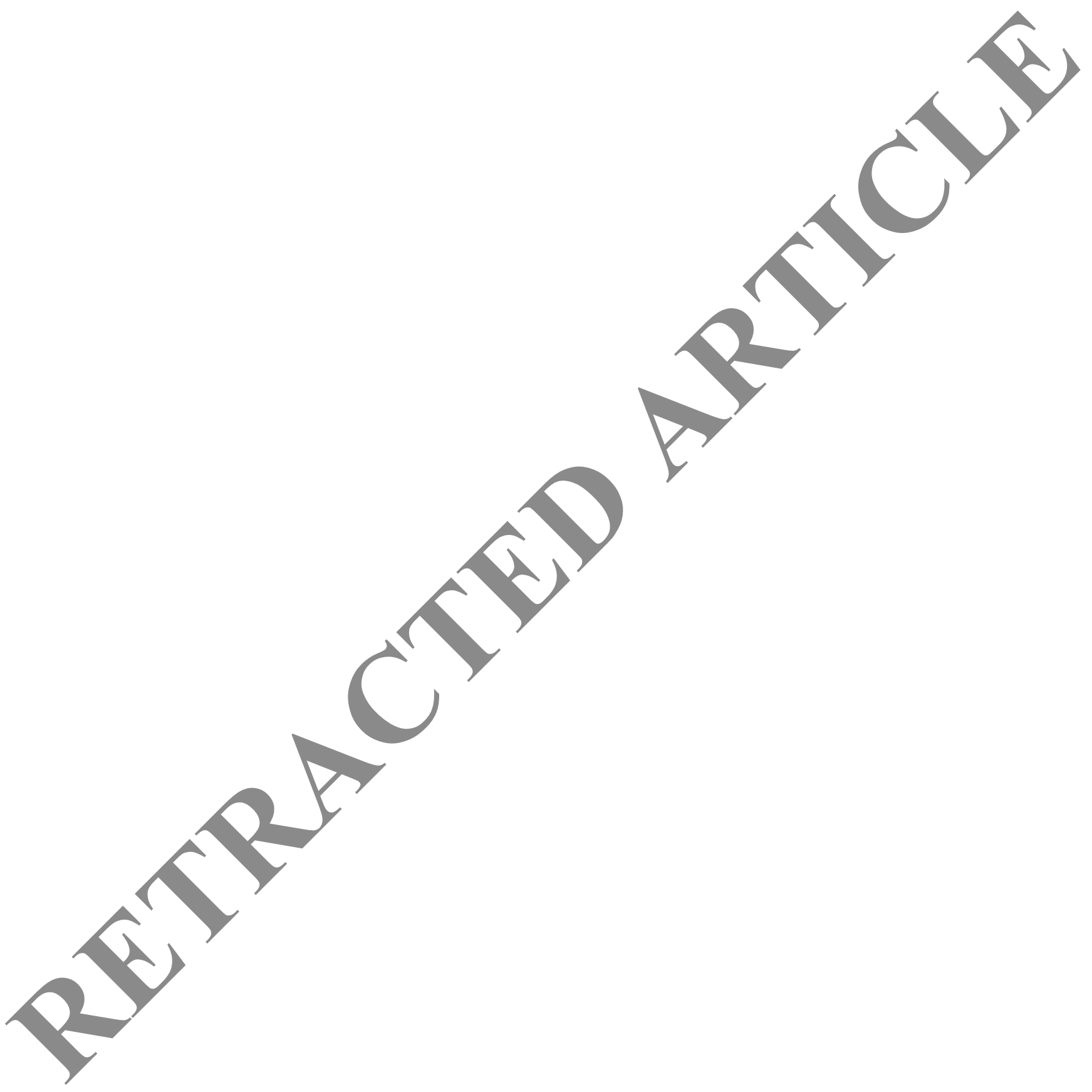




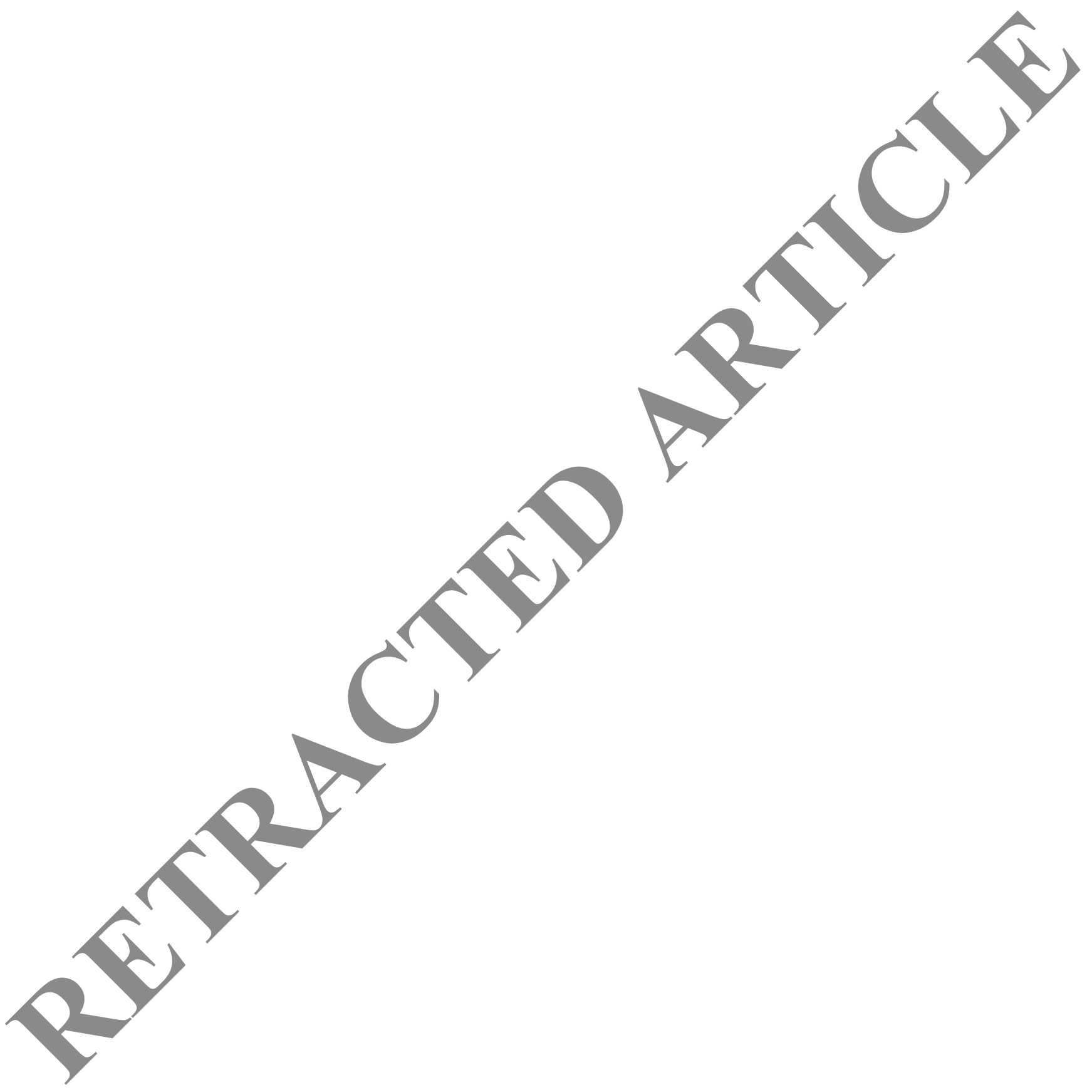




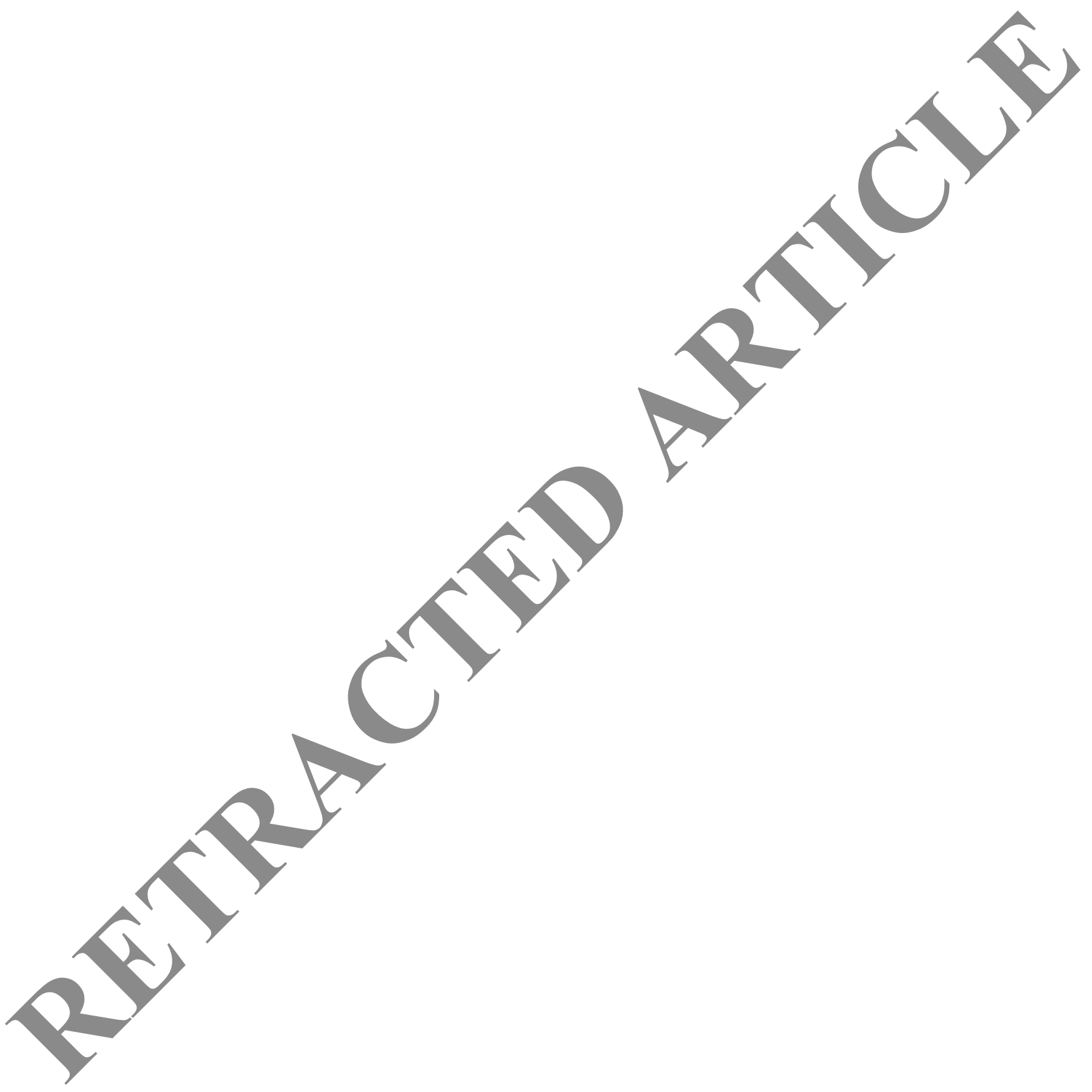

